\title{
Sequencing and bioinformatics analysis of the differentially expressed genes in herniated discs with or without calcification
}

\author{
JIA SHAO, MIAO YU, LIANG JIANG, FENGLIANG WU and XIAOGUANG LIU \\ Department of Orthopedics, Peking University Third Hospital, Beijing 100191, P.R. China
}

Received December 9, 2015; Accepted December 1, 2016

DOI: $10.3892 / \mathrm{ijmm} .2016 .2821$

\begin{abstract}
The purpose of this study was to detect the differentially expressed genes between ossified herniated discs and herniated discs without ossification. In addition, we sought to identify a few candidate genes and pathways by using bioinformatics analysis. We analyzed 6 samples each of ossified herniated discs (experimental group) and herniated discs without ossification (control group). Purified mRNA and cDNA extracted from the samples were subjected to sequencing. The NOISeq method was used to statistically identify the differentially expressed genes (DEGs) between the 2 groups. An in-depth analysis using bioinformatics tools based on the DEGs was performed using Gene Ontology (GO) enrichment, Kyoto Encyclopedia of Genes and Genomes (KEGG) pathway enrichment, and protein-protein interaction network analysis. The top 6 DEGs were verified using reverse transcription-quantitative polymerase chain reaction (RT-qPCR). A total of 132 DEGs was detected. A total of 129 genes in the ossified group were upregulated and 3 genes were found to be downregulated as compared to the control group. The top 3 cellular components in $\mathrm{GO}$ ontologies analysis were extracellular matrix components. GO functions were mainly related to the glycoprotein in the cell membrane and extracellular matrix. The GO process was related to completing response to stimulus, immune reflex and defense. The top 5 KEGG enrichment pathways were associated with infection and inflammation. Three of the top
\end{abstract}

Correspondence to: Dr Xiaoguang Liu, Department of Orthopedics, Peking University Third Hospital, 49 North Garden Road, Haidian, Beijing 100191, P.R. China

E-mail:xglius@126.com

Abbreviations: CT, computed tomography; DEGs, differentially expressed genes; GO, Gene Ontology; KEGG, Kyoto Encyclopedia of Genes and Genomes; PCR, polymerase chain reaction; BMPs, bone morphogenetic proteins; Runx2, runt-related transcription factor 2; SNPs, single nucleotide polymorphisms; BGI, Beijing Genomics Institute; BIND, Biomolecular Interaction Network Database; BioGRID, Biological General Repository for Interaction Datasets; HPRD, Human Protein Reference Database; Gla, $\gamma$-carboxyglutamic acid

Key words: ossified disc, sequencing, differentially expressed genes, spinal disc herniation, bioinformatics analysis
20 DEGs [sclerostin (SOST), WNT inhibitory factor 1 (WIF1) and secreted frizzled related protein 4 (SFRP4)] were related to the inhibition of the Wnt pathway. The ossified discs exhibited a higher expression of the top 6 DEGs [SOST, joining chain of multimeric IgA and IgM (IGJ; also known as JCHAIN), defensin alpha 4 (DEFA4), SFRP4, proteinase 3 (PRTN3) and cathepsin G (CTSG)], with the associated P-values of 0.045 , $0.000,0.008,0.010,0.015$ and 0.002 , respectively, as calculated by the independent sample t-test. The gene expression profiling of the 2 groups revealed differential gene expression. Thus, our data suggest that Wnt pathway abnormality and local inflammation may be related to disc ossification.

\section{Introduction}

Spinal disc herniation is known as degenerated discs protruding into the spinal canal or the foraminal canal (1). The associated symptoms, such as lower back pain and radiating leg pain (2) tend to severely affect the quality of life of patients and impose a massive economic burden on society $(3,4)$. Herniated discs may exhibit severe ossification which may adhere to the epidural membrane, and can lead to ossification of the epidural membrane with a high risk of cerebrospinal fluid leakage and this complicates surgical treatment (5). However, the mechanisms of disc ossification remain unclear.

Herniated disc ossification is related to disc degeneration. Patients with a prolonged history of spinal disc herniation are susceptible to disc ossification (6). Degenerated disc cells have been shown to express bone morphogenetic proteins (BMPs) and their receptors (7). Although some studies have documented the BMP-induced stimulation of chondrogenesis and the regeneration of the extracellular matrix of the intervertebral disc $(8,9)$, another study demonstrated no effect of BMPs in preventing the degeneration of the intervertebral disc, but demonsrated that it led to intervertebral disc calcification (10). The expression of runt-related transcription factor 2 (Runx2), a key transcription factor for chondrocyte hypertrophic differentiation (11), has been shown to be upregulated in the degenerative discs of dogs (12) and humans (13). Unlike dystrophic calcification, disc ossification is a positive osteogenic process associated with osteoblasts (14); however, the origin of osteogenic cells remains unclear. According to Risbud et al, these osteogenic cells differentiate from the initial cells residing in intervertebral disc tissue (15). Studies have demonstrated the osteogenic potential of annulus fibrosus cells which leads to ossification by 
osteogenic inductive stimulation $(16,17)$. Owing to the linkage between ossification and degeneration, the local environmental factors appear to be instrumental in causing disc ossification.

The association of disc degeneration (or herniation) and inflammation is well documented, with several inflammatory factors now known to be implicated in the degeneration of intervertebral discs (18). However, whether these inflammatory factors are the cause of degeneration or the result of degeneration is yet to be completely understood. The presence of local inflammation and angiogenesis in herniated and ossified discs indicates that the ossification process may be related to these two processes (19). However, whether the inflammatory and angiogenic factors involved in disc herniation are akin to those in ossified discs has yet to be determined.

High-throughput sequencing is a useful method to detect the underlying molecular mechanisms of any disease and can provide valuable pointers to guide future research. There are very few studies which have applied bioinformatics analysis and identified group of genes and single nucleotide polymorphisms (SNPs) associated with intervertebral disc degeneration and disc-related disorders (20). These studies have mainly centered on the genes involved in degeneration of the intervertebral discs, and do not dwell on the osteogenic process in the degenerated discs. Screening for differentially expressed genes (DEGs) focuses on the mRNA expression in a tissue, and can allow for the detection of different genes between 2 groups, and which in turn may help to unravel the probable mechanisms of a certain pathogenesis at the gene level.

The purpose of this study was to detect the DEGs between ossified and non-ossified herniated discs. In addition, bioinformatics tools were employed to identify potential candidate genes and pathways for further research.

\section{Materials and methods}

Case selection and grouping. Patients diagnosed with lumbar intervertebral disc herniation or herniation combined with spinal canal stenosis at the Peking University Third hospital from February, 2015 to May, 2015 were included in the study. All cases were scheduled for lumbar spinal surgery for the first time. We sampled 6 discs from 6 patients with ossified intervertebral discs as the experiment group. After sampling, these cases were confirmed by computed tomography (CT) scan and verified by micro CT scan as shown in Fig. 1. Another 6 iscs from 6 patients suffering from intervertebral disc herniation without disc ossification served as the control group. Patients with gout, hypercalcemia, congenital bone metabolism disorders or bone malformation were excluded from the study. This study was approved by Medical Scientific Research Ethics Committee of Peking University Third Hospital, Beijing, China with the certification number 2015006. Written informed consent was obtained from all patients prior to obtaining the samples.

Reagents. TRIzol reagent (15596-026) for total RNA extraction was obtained from Invitrogen, Life Technologies (Carlsbad, CA, USA). The RevertAid first-strand cDNA synthesis kit (K1633) from ThermoScientific (Waltham, MA, USA) was used for reverse transcription. FastStart Universal SYBR-Green Master from Roche (Basel, Switzerland) was used for carrying out quantitative polymerase chain reaction (qPCR). Primers were synthesized by Invitrogen Biotechnology Co., Ltd. (Shanghai, China).

Sampling. After the laminas were removed by the posterior lumbar spinal procedure, the nerve root and the posterior longitudinal ligament of the herniated side of the intervertebral disc was retracted, leaving space for a circular incision to be made in the annular fibrosus. A nucleus pulposus clamp was used to extract the first piece of the herniated disc, and used as a specimen. For the purpose of uniformity, totally ossified discs which could not be sampled by this method were excluded. Following their excision, the specimens were immediately kept in frozen storage tubes and placed in liquid nitrogen. As the pre-procedure CT scan images had already been obtained, the specimens were directly transported for the micro CT scan and later stored at $-80^{\circ} \mathrm{C}$ until further analyses.

Micro CT scan. A Siemens Inveon Micro CT scanner (Siemens Medical Solutions, Knoxville, TN, USA) was used to analyze the specimens using the following parameters: X-ray beam voltage, $80 \mathrm{kV}$; current, $500 \mu \mathrm{A}$; and effective resolution $13.6 \mu \mathrm{m}$. Referring to the semi-quantitative grading criteria of Rutges et al (14), the following criteria were adopted for this analysis: the absence of calcification was indicated as -; the presence of a single area of calcification as \pm ; the presence of 2 clear areas of calcification as + ; and the clear presence of multiple areas of calcification as ++ . We designated - or \pm for a negative CT scan as the control group; ++ with positive CT scan as experiment group. At least 2 of the authors collaborated to assess the ossification from the CT radiograph and the ossification grade according to the micro CT analysis.

$m R N A$ extraction. Following micro-CT analysis, the ossified disc group was considered as the experiment group, and the degenerated herniated disc group without ossification as the control group. For the mRNA extraction, the specimens were treated with TRIzol reagent and grinded sufficiently. The specimens were then centrifuged $\left(8000 \mathrm{x} \mathrm{g}, 4^{\circ} \mathrm{C}\right)$ and reconstituted in methenyltrichloride and propyl alcohol. The total RNA was stored at $-80^{\circ} \mathrm{C}$ for further sequencing and verification.

Sequencing and bioinformatics analysis. Sequencing was performed at the Beijing Genomics Institute (BGI). The total RNA samples were treated with DNase I to avoid DNA contamination. The enriched mRNA was mixed and fragmented into short fragments using fragmentation buffer. After the double-strand cDNA fragments were synthesized and purified, end reparation and 3'-end single nucleotide A (adenine) addition was performed. Finally, the sequencing adaptors to the fragments were ligated. Following enrichment by PCR amplification, the fragments were sequenced using a Illumina HiSeq $^{\mathrm{TM}} 2000$ sequencer (Illumina Inc., Santiago, CA, USA). Primary sequencing data generated by Illumina $\mathrm{HiSeq}^{\mathrm{TM}} 2000$ was referred to as raw reads. The raw reads are filtered into clean reads which were aligned to the reference sequences subsequently by using the Burrows-Wheeler Alignment BWA (21)/ Bowtie2 (22) tool. The NOISeq (23) method was used to screen DEGs between 2 groups. Furthermore, an in depth analysis using bioinformatics tools based on the DEGs was performed, including GO enrichment analysis, KEGG pathway enrichment 
Table I. Sequences of primers for RT-qPCR.

\begin{tabular}{lll}
\hline Gene & \multicolumn{1}{c}{ Upstream primer } & \multicolumn{1}{c}{ Downstream primer } \\
\hline GAPDH & AGCCACATCGCTCAGACAC & GCCCAATACGACCAAATCC \\
SOST & GTGGCAGGCGTTCAAGAATG & CCCGGTTCATGGTCTTGTTG \\
IGJ & GGAGTCCTGGCGGTTTTTAT & GGATCTTCGGAAGAACGGAT \\
DEFA4 & GCCCTCCTCGCTGCTATTCT & ATGTCCTGGTCTTCTGGCCC \\
SFRP4 & ACTGCGAGCCCCTCATGAAG & CTTCAGGCGAGATGCACACG \\
PRTN3 & CCTGCAGGAGCTCAATGTCA & GAGTCTCCGAAGCAGATGCC \\
CTSG & AACGGAAGGCTGCCTTCAAG & CTGGAGGAACCCCTGACGAC
\end{tabular}

PCR, polymerase chain reaction; GAPDH, glyceraldehyde 3-phosphate dehydrogenase.

A

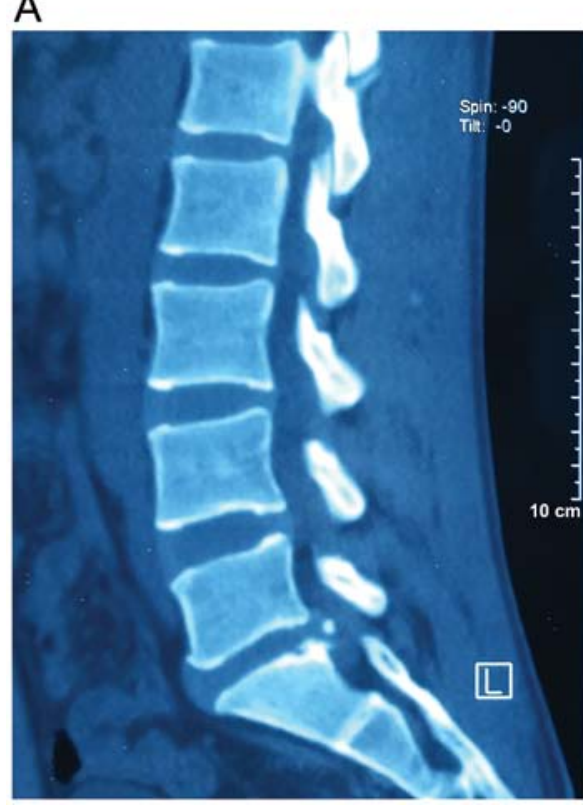

B

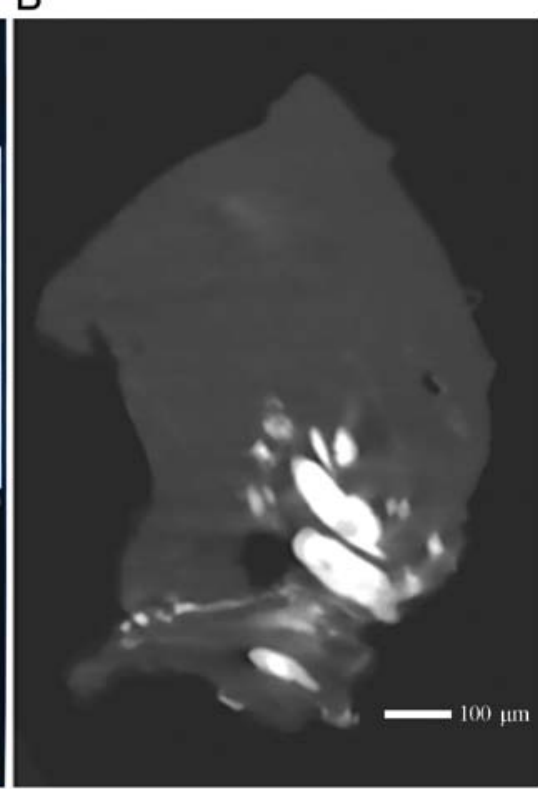

Figure 1. CT and micro CT imaging of ossified disc. (A) CT scan showing the ossified spot in the herniated disc; (B) micro CT screening confirmed the ossification. $\mathrm{CT}$, computed tomography.

analysis, and protein-protein interaction network analysis. After mapping all the DEGs to GO terms according to the database in the website, http://www.geneontology.org/, the numbers for each GO term were calculated; the significantly enriched GO terms were found by using 'GO::TermFinder' tool on the website, http://www.yeastgenome.org/help/analyze/go-termfinder. All the DEGs annotated in the GO database were used to perform GO functional classification using WEGO (24) software for understanding the distribution of gene functions from the macro level. DEGs for KEGG enrichment analysis were mapped to the KEGG database. After the GO and KEGG data were analyzed, a P-value was obtained. The protein-protein interaction network of the top 20 DEGs was completed based on the local database of BGI which integrated the Biomolecular Interaction Network Database (BIND), Biological General Repository for Interaction Datasets (BioGRID) and the Human Protein Reference Database (HPRD).

Verification. ELK2P was tagged for the member of the ETS oncogene family, and the expression of bone gamma-carbox- yglutamate protein (BGLAP) had been tested in our previous study (25). Hence, we verified the top 6 DEGs excluding ELK2P and BGLAP by RT-qPCR after the screening of the DEGs. Reverse transcription for cDNA synthesis was performed as per the manufacturer's instructions (RevertAid First Strand cDNA synthesis kit). Glyceraldehyde 3-phosphate dehydrogenase (GAPDH) was used as the reference gene, and qPCR was performed as per the protocol recommended by the manufacturer (FastStart Universal SYBR-Green Master) with the primers listed in Table I. The PCR program was set as follows: pre-denaturation at $95^{\circ} \mathrm{C}$ for $10 \mathrm{~min}$, cooling to $60^{\circ} \mathrm{C}$ for $15 \mathrm{sec}$, held for $60 \mathrm{sec}$ for 40 cycles, elongation at $60^{\circ} \mathrm{C}$ for $5 \mathrm{~min}$, and then an increase from $75^{\circ} \mathrm{C}$ to $95^{\circ} \mathrm{C}$ at $1^{\circ} \mathrm{C} / 20 \mathrm{sec}$ to obtain the melting curve. Relative gene expression was normalized to the control group by referring to the Livak and Schmittgen method (26).

Statistical analysis. The NOISeq method was used to assess the DEGs in the 2 groups using the following criteria as default: fold-change $\geq 2.0$ and diverge probability $\geq 0.8$. The associ- 
ated P-value for the GO and KEGG enrichment analysis was subjected to Bonferroni Correction and a corrected P-value obtained. A Corrected P-value $<0.05$ was considered indicative of a statistically significant difference. Statistical analysis of the verification was performed using SPSS 20.0 (International Business Machines Corporation, Armonk, NY, USA). An independent sample t-test was used to analyze the RT-qPCR verification results between the ossified and non-ossified degeneration group. Inter-group differences with an associated P-value $<0.05$ were considered as statistically significant.

\section{Results}

Sequencing and raw data filtering. We sequenced 12 samples by RNA-Seq technology and generated an average of $13,127,595.5$ raw reads. After the low quantity reads were filtered, an average of 12,994,408 clean reads was acquired. The data pertaining to each sample are listed in Table II. The numbers of expressed genes and the expression ratio in each specimen are shown in Fig. 2.

Differentially expressed genes. A total of 132 DEGs was detected in this study. A total of 129 in the ossification group were upregulated as compared to those in the control group, while 3 genes were found to be downregulated. The top 20 DEGs according to the probability value are listed in Table III.

GO enrichment analysis. The GO functional classification used in this study is illustrated in Fig. 3. Referring to the corrected P-values, the top 3 enrichment terms in all the $3 \mathrm{GO}$ ontologies were listed: cellular component, molecular function and biological process (Table IV).

KEGG enrichment analysis. The most enriched pathways based on KEGG were asthma, malaria, African trypanosomiasis, staphylococcus aureus infection, collecting duct acid secretion and primary immunodeficiency. The top 10 KEGG enriched pathways are listed in Table V.

Protein-protein interaction network analysis. Protein-protein interaction network analysis was performed using the coding proteins of the top 20 DEGs based on the interaction network database BIND; the results are illustrated using Medusa software (27) (Fig. 4).

Verification by RT-qPCR. The results of RT-PCR are shown in Fig. 5. The ossified discs exhibierd a higher expression of the top 6 DEGs: SOST, IGJ, DEFA4, SFRP4, PRTN3 and CTSG, with associated P-values of $0.045,0.000,0.008,0.010,0.015$ and 0.002 , respectively, and F-values of 4.868, 159.719, 10.201, $8.401,8.266$ and 17.783 , respectively, calculated using an independent sample t-test. The results were consistent with those of the DEG sequencing.

\section{Discussion}

Disc ossification is not a rare phenomenon (28). The ossification rate is known to correlate with the degeneration grade of intervertebral discs and the Modic type endplate (19). The

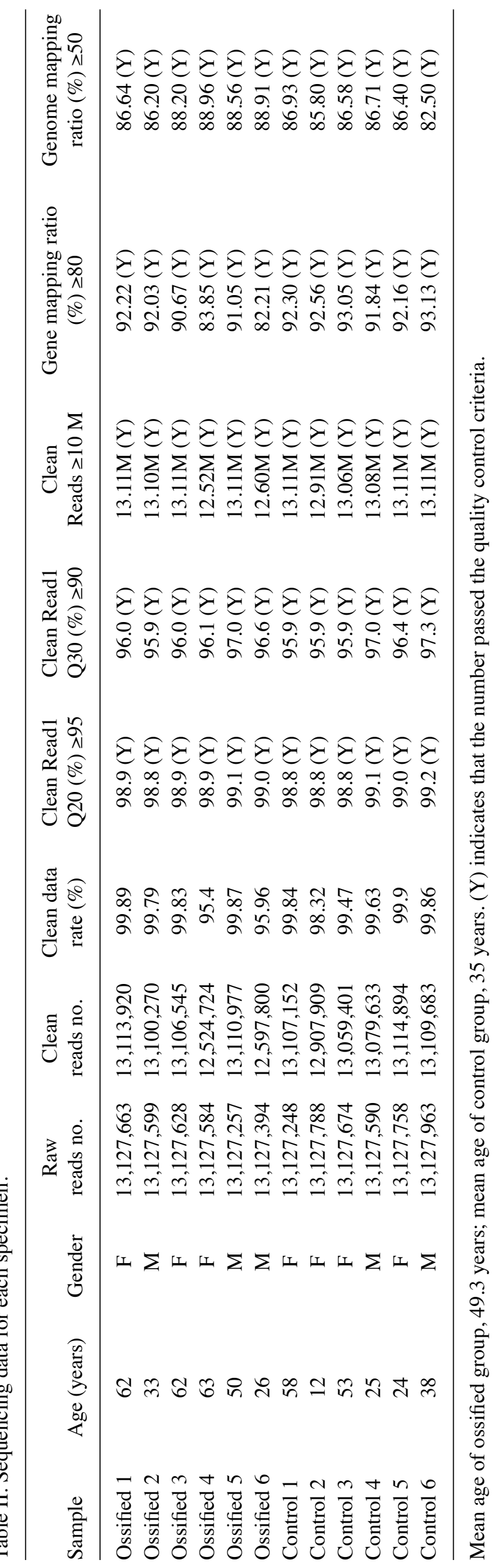


Table III. Top 20 DEGs.

\begin{tabular}{|c|c|c|c|c|c|}
\hline Gene ID & Symbol & $\begin{array}{c}\log 2 \text { Ratio } \\
\text { (ossified/control) }\end{array}$ & Probability & $\begin{array}{l}\text { Up/down } \\
\text { regulation }\end{array}$ & Description \\
\hline 50964 & SOST & 9.658888588 & 0.980396 & Up & Sclerostin \\
\hline 3512 & IGJ & 6.673912182 & 0.967813 & Up & Immunoglobulin J polypeptide \\
\hline 632 & BGLAP & 5.492969178 & 0.962151 & Up & Bone $\gamma$-carboxyglutamate (gla) protein \\
\hline 2003 & ELK2AP & 5.437789846 & 0.960819 & Up & ELK2A \\
\hline 1669 & DEFA4 & 5.317314168 & 0.956617 & Up & Defensin, $\alpha 4$ \\
\hline 6424 & SFRP4 & 5.055694219 & 0.95017 & Up & Secreted frizzled-related protein 4 \\
\hline 5657 & PRTN3 & 4.933061142 & 0.947346 & Up & Proteinase 3 \\
\hline 1511 & CTSG & 4.657946704 & 0.941332 & Up & Cathepsin G \\
\hline 1991 & ELANE & 4.591945637 & 0.941047 & Up & Elastase \\
\hline 566 & AZU1 & 4.584099727 & 0.940888 & Up & Azurocidin 1 \\
\hline 100423062 & IGLL5 & 4.310197783 & 0.933947 & Up & Immunoglobulin $\lambda$-like polypeptide 5 \\
\hline 2812 & GP1BB & 10.73075316 & 0.931232 & Up & Glycoprotein Ib (platelet), $\beta$ polypeptide \\
\hline 63924 & CIDEC & 6.76165846 & 0.930184 & Up & Cell death-inducing DFFA-like effector c \\
\hline 3543 & IGLL1 & 5.1749338 & 0.928683 & Up & Immunoglobulin $\lambda$-like polypeptide 1 \\
\hline 728358 & DEFA1B & 3.988886669 & 0.92734 & Up & Defensin, $\alpha 1 \mathrm{~B}$ \\
\hline 4353 & MPO & 4.209517648 & 0.927108 & Up & Myeloperoxidase \\
\hline 55363 & HEMGN & 4.89235857 & 0.927006 & Up & Hemogen \\
\hline 6037 & RNASE3 & 4.64090047 & 0.926718 & Up & Ribonuclease, RNase A family, 3 \\
\hline 6036 & RNASE2 & 4.154822975 & 0.919141 & Up & Ribonuclease, RNase A family, 2 \\
\hline 11197 & WIF1 & 5.058808822 & 0.917018 & Up & WNT inhibitory factor 1 \\
\hline
\end{tabular}

DEGs, differentially expressed genes.

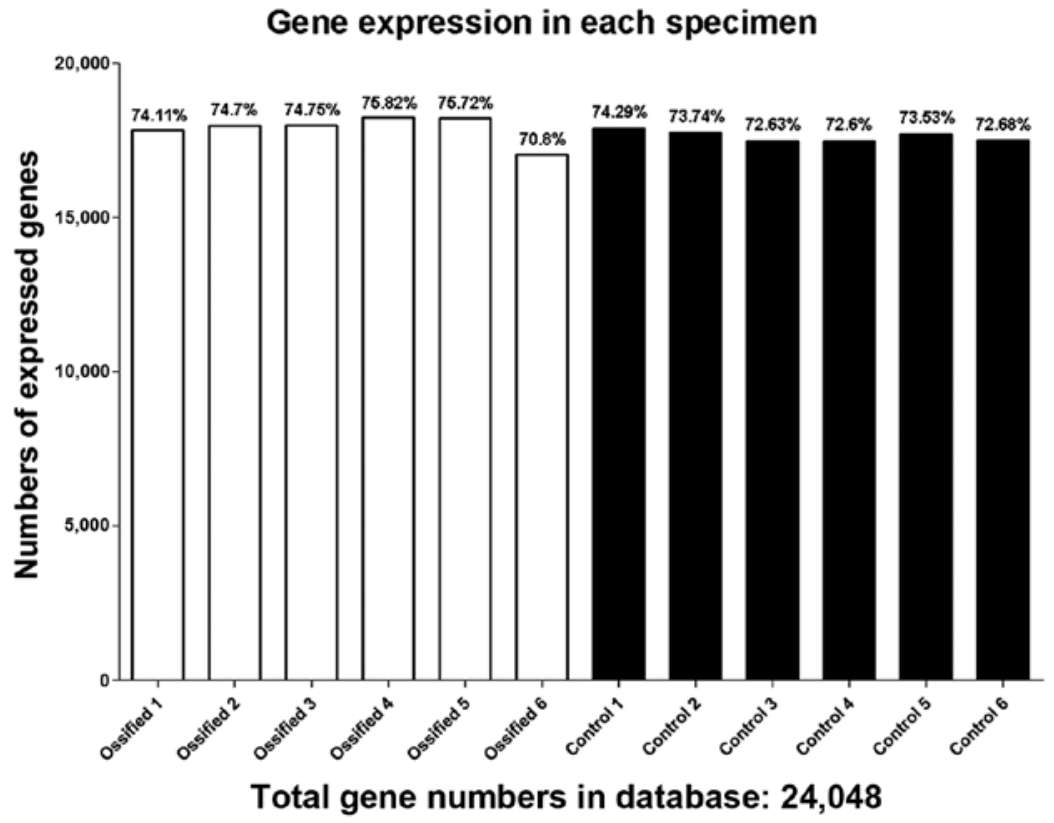

Figure 2. Gene expression in each specimen. With a total gene number of 24,048 in the database, the numbers of expressed genes in our study ranged from 17,026 in 'ossified 6' to 18,232 in 'ossified 4'; the expression ratios were from 70.8 to $75.82 \%$.

underlying mechanisms responsible for the ossification of intervertebral discs are unclear. To the best of our knowledge, the present study is the first to determine the DEGs between ossified discs and non-ossified discs by employing highthroughput sequencing technology. After sequencing, the
NOISeq method was applied to determine the DEGs. These results were verified and were found to be consistent with those of DEGs obtained by performing RT-qPCR.

We selected the top 20 DEGs and focused on some of these genes as our candidate genes for further research. According 
Table IV. Top 3 enrichment terms in all three GO ontologies.

\begin{tabular}{|c|c|c|c|c|}
\hline GO ontologies & GO terms & $\begin{array}{l}\text { Cluster } \\
\text { frequency }\end{array}$ & $\begin{array}{l}\text { Genome } \\
\text { frequency of use }\end{array}$ & $\begin{array}{l}\text { Corrected } \\
\text { P-value }\end{array}$ \\
\hline $\begin{array}{l}\text { Cellular } \\
\text { component }\end{array}$ & $\begin{array}{l}\text { GO:0044421 - extracellular } \\
\text { region part }\end{array}$ & $32(101), 31.7 \%$ & 1055 (16090), 6.6\% & $1.70 \mathrm{E}-12$ \\
\hline $\begin{array}{l}\text { Cellular } \\
\text { component }\end{array}$ & $\begin{array}{l}\text { GO:0005576 - extracellular } \\
\text { region }\end{array}$ & $32(101), 31.7 \%$ & 1077 (16090), 6.7\% & $3.02 \mathrm{E}-12$ \\
\hline $\begin{array}{l}\text { Cellular } \\
\text { component }\end{array}$ & $\begin{array}{l}\text { GO:0016023 - cytoplasmic } \\
\text { membrane- bounded vesicle }\end{array}$ & $12(101), 11.9 \%$ & 609 (16090), 3.8\% & 0.03246 \\
\hline $\begin{array}{l}\text { Molecular } \\
\text { function }\end{array}$ & $\begin{array}{l}\text { GO:0030247 - polysaccharide } \\
\text { binding }\end{array}$ & $11(95), 11.6 \%$ & $159(15165), 1.0 \%$ & $3.48 \mathrm{E}-07$ \\
\hline $\begin{array}{l}\text { Molecular } \\
\text { function }\end{array}$ & $\begin{array}{l}\text { GO:0001871 - pattern } \\
\text { binding }\end{array}$ & $11(95), 11.6 \%$ & $169(15165), 1.1 \%$ & $6.60 \mathrm{E}-07$ \\
\hline $\begin{array}{l}\text { Molecular } \\
\text { function }\end{array}$ & $\begin{array}{l}\text { GO:0005539 - glycosaminoglycan } \\
\text { binding }\end{array}$ & $10(95), 10.5 \%$ & $142(15165), 0.9 \%$ & $1.54 \mathrm{E}-06$ \\
\hline $\begin{array}{l}\text { Biological } \\
\text { process }\end{array}$ & $\begin{array}{l}\text { GO:0006952 - defense } \\
\text { response }\end{array}$ & $25(108), 23.1 \%$ & $601(14596), 4.1 \%$ & $6.26 \mathrm{E}-10$ \\
\hline $\begin{array}{l}\text { Biological } \\
\text { process }\end{array}$ & $\begin{array}{l}\text { GO:0002376 - immune } \\
\text { system process }\end{array}$ & $33(108), 30.6 \%$ & 1106 (14596), $7.6 \%$ & $8.06 \mathrm{E}-10$ \\
\hline $\begin{array}{l}\text { Biological } \\
\text { process }\end{array}$ & $\begin{array}{l}\text { GO:0050896 - response } \\
\text { to stimulus }\end{array}$ & $54(108), 50.0 \%$ & $3380(14596), 23.2 \%$ & 4.94E-07 \\
\hline
\end{tabular}

GO, Gene Ontology.

Table V. The top 10 KEGG enriched pathways.

\begin{tabular}{|c|c|c|c|c|}
\hline Pathway ID & Pathway & $\begin{array}{c}\text { DEGs with pathway } \\
\text { annotation } \\
(108)\end{array}$ & $\begin{array}{c}\text { All genes with } \\
\text { pathway annotation } \\
\qquad(17252)\end{array}$ & P-value \\
\hline ko05310 & Asthma & $7(6.48 \%)$ & $47(0.27 \%)$ & $1.58 \mathrm{E}-08$ \\
\hline ko05144 & Malaria & $7(6.48 \%)$ & $76(0.44 \%)$ & 4.75E-07 \\
\hline ko05143 & African trypanosomiasis & $6(5.56 \%)$ & $54(0.31 \%)$ & $1.06 \mathrm{E}-06$ \\
\hline ko05150 & Staphylococcus aureus infection & $6(5.56 \%)$ & $139(0.81 \%)$ & 0.00024 \\
\hline ko04966 & Collecting duct acid secretion & $4(3.7 \%)$ & $51(0.3 \%)$ & 0.00029 \\
\hline ko05340 & Primary immunodeficiency & $4(3.7 \%)$ & $61(0.35 \%)$ & 0.00058 \\
\hline ko04610 & Complement and coagulation cascades & $6(5.56 \%)$ & $181(1.05 \%)$ & 0.00097 \\
\hline ko05322 & Systemic lupus erythematosus & $6(5.56 \%)$ & $188(1.09 \%)$ & 0.0012 \\
\hline ko04640 & Hematopoietic cell lineage & $5(4.63 \%)$ & $152(0.88 \%)$ & 0.0027 \\
\hline ko03320 & PPAR signaling pathway & $4(3.7 \%)$ & $135(0.78 \%)$ & 0.01 \\
\hline
\end{tabular}

KEGG, Kyoto Encyclopedia of Genes and Genomes; DEGs, differentially expressed genes.

to the diverge probability calculated by the NOISeq method, SOST was the topmost DEG. The coding product of SOST is sclerostin, a glycoprotein secreted by osteocytes, which is an important marker of late-stage osteoblasts/osteocytes. An earlier study suggested sclerostin to act as a BMP-inhibitor by competitively binding to BMP receptors, thereby inhibiting osteoblast differentiation and osteogenesis induced by BMPs (29). By contrast, other studies have suggested that the inhibitory effect of sclerostin was mediated through the Wnt signaling pathway and not by BMP $(30,31)$. Since there are contradicting results related to the effect of sclerostin on the ossification of discs (32), further studies are required to delineate its role.

We were interested in another DEG, BGLAP, which codes for osteocalcin protein. Osteocalcin is an important protein marker of late stage osteogenesis secreted by osteoblasts (33). 


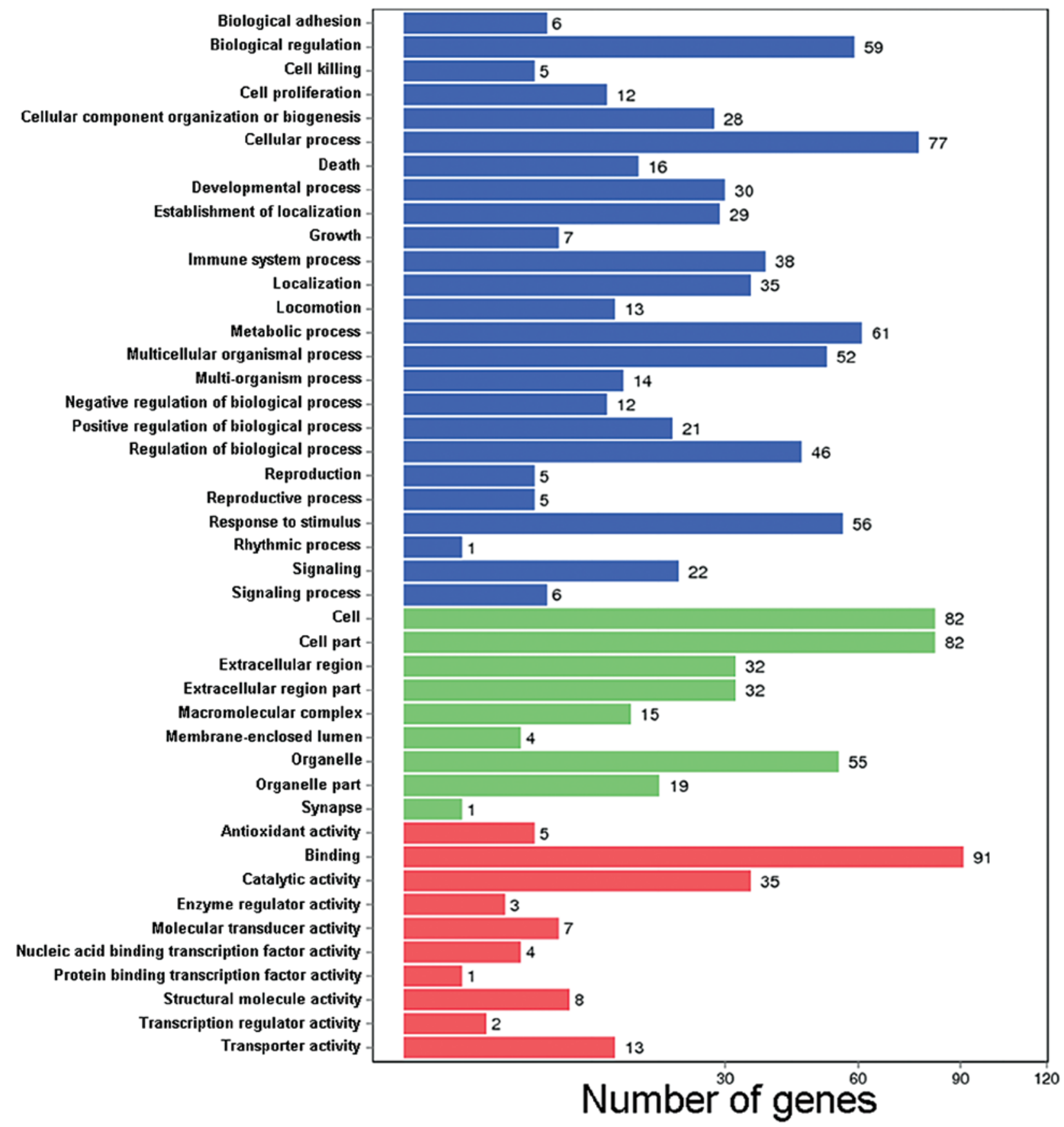

Figure 3. GO functional classification on DEGs. The x-axis represents the number of DEGs available at the top of the column. The y-axis represents GO terms. All GO terms are grouped into 3 ontologies: biological process, cellular component and molecular function; blue indicates biological process, brown indicates cellular component and orange indicates molecular function. DEGs, differentially expressed genes; GO, Gene Ontology.

It is abundant in $\gamma$-carboxyglutamic acid (Gla) residue and can combine with the calcium ions in hydroxyapatite to form osteoid element $(34,35)$. The upregulated expression of SOST and BGLAP indicated that the calcification of the intervertebral disc was not a dystrophic calcification, but an osteogenic process involving the participation of osteoblasts. This observation is consistent with some earlier reports $(14,15)$, and it also serves to verify the rationale behind our sampling process using CT and micro CT scan.

All the top 3 cellular components of GO ontologies analysis based on DEGs were extracellular components which indicate that these proteins are of the secretory type. GO functions are mainly related to the interaction of the glycoprotein in the cell membrane with the extracellular matrix. The GO processes are associated with completing response to stimulus, immune reflex and defense.

The top 5 KEGG enrichment pathways are associated with infection and inflammation. On scrutinizing the top 20 DEGs, we found that 3 genes: SOST, WIF1 and SFRP4 were related to the inhibition of the Wnt signaling pathway (36-38). SOST, the topmost DEG, is not termed by KEGG. The KEGG enrichment pathway analysis was performed using all the DEGs, which, to some extent, could have served to obscure the identification of the Wnt pathway. We believe that disc ossification is associated 

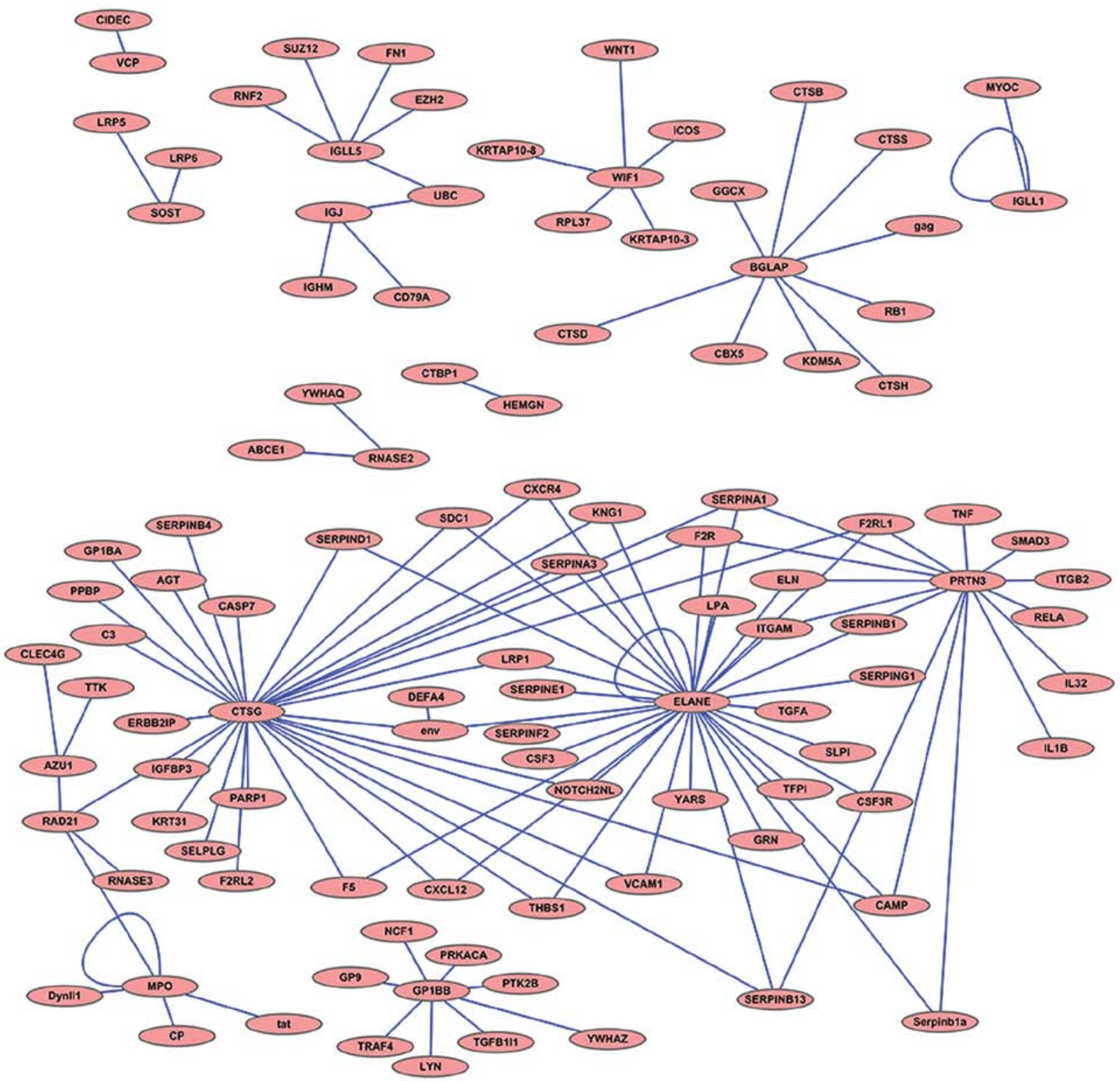

Figure 4. Protein-protein interaction network of the coding proteins of the top 20 DEGs. DEGs, differentially expressed genes.

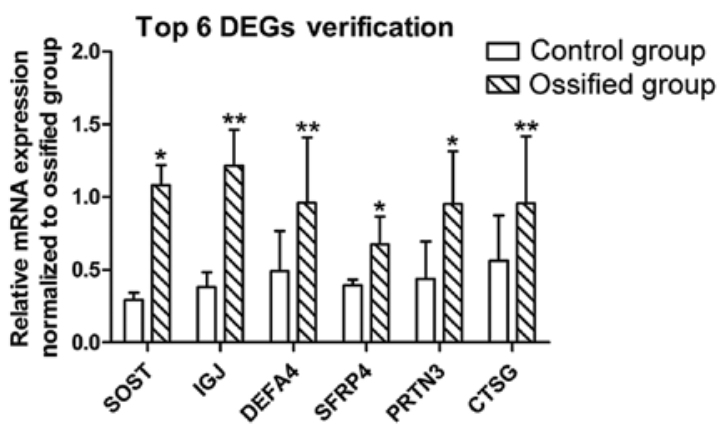

Figure 5. Verification of top 6 DEGs. The x-axis represents the top 6 DEGs; each DEG contains the comparison of the ossified and control groups. The y-axis represents the relative mRNA expression of the DEG in each group normalized to the ossified group. ${ }^{*} \mathrm{P}<0.05$ and ${ }^{* *} \mathrm{P}<0.01$ as compared to the control group as shown by an independent sample t-test. DEGs, differentially expressed genes.

with the inhibition of the Wnt pathway due to the identification of several gene products related to Wnt inhibition. Whether the ossification is caused by Wnt pathway inhibition or Wnt was inhibited by the ossification is still not clear from the findings of our study.

Degenerative discs do exhibit the expression of BMP-2 (39), which is a widely known inducer of bone formation. Furthermore, the existence of crosstalk between BMP-2 and Wnt pathways in the degenerated discs suggests that BMP-2 pathway can inhibit the Wnt pathway (40). However in a recent study, Wnt/ $\beta$-catenin signaling was found to activate BMP-2 expression in osteoblasts (41). Taking into consideration the association between the Wnt/ $\beta$-catenin signaling and BMP-2 pathway, we hypothesized that the BMP-2 pathway may play a role in the the overexpression of Wnt inhibitors. This needs to be further investigated in in vitro cell experiments.

Although inflammation is thought to play an important role in intervertebral disc degeneration and herniation (18), definitive evidence of this association has yet to be obtained. Several inflammatory factors, such as tumor necrosis factor (TNF)- $\alpha$, interleukin (IL)-1 $\beta$, IL-6 and IL-8, have been implicated in 
the causation of disc degeneration and herniation (42-45). By contrast, this study found that none of the DEGs encoded for these inflammatory factors. We found a comprehensive expression of inflammation-related factors, such as defencin $\alpha 4$, proteinase 3 , cathepsin $\mathrm{G}$, elastase, azurocidin 1 and defensin $\alpha 1 \mathrm{~B}$, which are encoded by the genes, DEFA4, PRTN3, CTSG, ELANE, AZU1 and DEFA1B. These genes were among the top 20 differentially expressed genes between the experimental and the control groups. As regards the link between the intervertebral disc calcification and inflammation around the herniated discs (19), as well as the association between inflammation and ossification (46), we believe that the inflammatory factors coding DEGs may be specifically related to disc ossification.

The main limitation of the present study is its descriptive nature. The abnormal Wnt pathway and the overexpression of some inflammation-related factors documented in this study appear to be two crucial elements involved in causing disc ossification. However, in vivo and in vitro studies are required to thoroughly assess this observed association. We performed an elementary study of the molecular mechanisms underlying disc ossification. We found a potential mechanism, which, however, needs to be further investigated as a step towards the development of gene therapy targeting disc ossification in the future. We believe that our study is helpful to finally elucidate out the mechanisms responsible for disc ossification, and patients may benefit from the prevention and treatment of herniated disc with ossification at the gene level.

\section{References}

1. Urban JP and Roberts S: Degeneration of the intervertebral disc. Arthritis Res Ther 5: 120-130, 2003.

2. Taher F, Essig D, Lebl DR, Hughes AP, Sama AA, Cammisa FP and Girardi FP: Lumbar degenerative disc disease: Current and future concepts of diagnosis and management. Adv Orthop 2012: 970752, 2012.

3. Parker SL, Godil SS, Mendenhall SK, Zuckerman SL, Shau DN and McGirt MJ: Two-year comprehensive medical management of degenerative lumbar spine disease (lumbar spondylolisthesis, stenosis, or disc herniation): a value analysis of cost, pain, disability, and quality of life: clinical article. J Neurosurg Spine 21: 143-149, 2014

4. Froud R, Patterson S, Eldridge S, Seale C, Pincus T, Rajendran D, Fossum $\mathrm{C}$ and Underwood $\mathrm{M}$ : A systematic review and metasynthesis of the impact of low back pain on people's lives. BMC Musculoskelet Disord 15: 50, 2014.

5. Barbanera A, Serchi E, Fiorenza V, Nina P and Andreoli A: Giant calcified thoracic herniated disc: considerations aiming a proper surgical strategy. J Neurosurg Sci 53: 25-26, 2009.

6. Prescher A: Anatomy and pathology of the aging spine. Eur J Radiol 27: 181-195, 1998

7. Takae R, Matsunaga S, Origuchi N, Yamamoto T, Morimoto N, Suzuki S and Sakou T: Immunolocalization of bone morphogenetic protein and its receptors in degeneration of intervertebral disc. Spine 24: 1397-1401, 1999.

8. Tim Yoon S, Su Kim K, Li J, Soo Park J, Akamaru T, Elmer WA and Hutton WC: The effect of bone morphogenetic protein-2 on rat intervertebral disc cells in vitro. Spine 28: 1773-1780, 2003.

9. Kim H, Lee JU, Moon SH, Kim HC, Kwon UH, Seol NH, Kim HJ, Park JO, Chun HJ, Kwon IK and Lee HM: Zonal responsiveness of the human intervertebral disc to bone morphogenetic protein-2. Spine 34: 1834-1838, 2009.

10. Haschtmann D, Ferguson SJ and Stoyanov JV: BMP-2 and TGF- $\beta 3$ do not prevent spontaneous degeneration in rabbit disc explants but induce ossification of the annulus fibrosus. Eur Spine J 21: 1724-1733, 2012.

11. Drissi H, Zuscik M, Rosier R and O'Keefe R: Transcriptional regulation of chondrocyte maturation: Potential involvement of transcription factors in OA pathogenesis. Mol Aspects Med 26 $169-179,2005$
12. Itoh H, Hara Y, Tagawa M, Kato T, Ochi H, Koga D, Okawa A and Asou Y: Evaluation of the association between runt-related transcription factor 2 expression and intervertebral disk aging in dogs. Am J Vet Res 73: 1553-1559, 2012.

13. Sato S, Kimura A, Ozdemir J, Asou Y, Miyazaki M, Jinno T, Ae K, Liu X, Osaki M, Takeuchi Y, et al: The distinct role of the Runx proteins in chondrocyte differentiation and intervertebral disc degeneration: findings in murine models and in human disease. Arthritis Rheum 58: 2764-2775, 2008.

14. Rutges JP, Duit RA, Kummer JA, Oner FC, van Rijen MH, Verbout AJ, Castelein RM, Dhert WJ and Creemers LB: Hypertrophic differentiation and calcification during intervertebral disc degeneration. Osteoarthritis Cartilage 18: 1487-1495, 2010.

15. Risbud MV, Guttapalli A, Tsai TT, Lee JY, Danielson KG, Vaccaro AR, Albert TJ, Gazit Z, Gazit D and Shapiro IM: Evidence for skeletal progenitor cells in the degenerate human intervertebral disc. Spine 32: 2537-2544, 2007.

16. Nosikova Y, Santerre JP, Grynpas MD and Kandel RA: Annulus fibrosus cells can induce mineralization: An in vitro study. Spine J 13: 443-453, 2013.

17. Jin L, Liu Q, Scott P, Zhang D, Shen F, Balian G and Li X: Annulus fibrosus cell characteristics are a potential source of intervertebral disc pathogenesis. PLoS One 9: e96519, 2014.

18. Molinos M, Almeida CR, Caldeira J, Cunha C, Gonçalves RM and Barbosa MA: Inflammation in intervertebral disc degeneration and regeneration. J R Soc Interface 12: 20150429, 2015.

19. Karamouzian S, Eskandary H, Faramarzee M, Saba M, Safizade H, Ghadipasha M, Malekpoor AR and Ohadi A: Frequency of lumbar intervertebral disc calcification and angiogenesis, and their correlation with clinical, surgical, and magnetic resonance imaging findings. Spine 35: 881-886, 2010.

20. Näkki A, Battié MC and Kaprio J: Genetics of disc-related disorders: Current findings and lessons from other complex diseases. Eur Spine J 23 (Suppl 3): S354-S363, 2014

21. Li H and Durbin R: Fast and accurate short read alignment with Burrows-Wheeler transform. Bioinformatics 25: 1754-1760, 2009.

22. Langmead B, Trapnell C, Pop M and Salzberg SL: Ultrafast and memory-efficient alignment of short DNA sequences to the human genome. Genome Biol 10: R25, 2009.

23. Tarazona S, García-Alcalde F, Dopazo J, Ferrer A and Conesa A: Differential expression in RNA-seq: A matter of depth. Genome Res 21: 2213-2223, 2011.

24. Ye J, Fang L, Zheng H, Zhang Y, Chen J, Zhang Z, Wang J, Li S, Li R, Bolund L and Wang J: WEGO: A web tool for plotting GO annotations. Nucleic Acids Res 34: W293-W297, 2006.

25. Shao J, Yu M, Jiang L, Wei F, Wu F, Liu Z and Liu X: Differences in calcification and osteogenic potential of herniated discs according to the severity of degeneration based on Pfirrmann grade: a cross-sectional study. BMC Musculoskelet Disord 17: $191,2016$.

26. Livak KJ and Schmittgen TD: Analysis of relative gene expression data using real-time quantitative PCR and the 2(-Delta Delta C(T)) Method. Methods 25: 402-408, 2001.

27. Hooper SD and Bork P: Medusa: A simple tool for interaction graph analysis. Bioinformatics 21: 4432-4433, 2005.

28. Chanchairujira K, Chung CB, Kim JY, Papakonstantinou O, Lee MH, Clopton P and Resnick D: Intervertebral disk calcification of the spine in an elderly population: Radiographic prevalence, location, and distribution and correlation with spinal degeneration. Radiology 230: 499-503, 2004.

29. Kusu N, Laurikkala J, Imanishi M, Usui H, Konishi M, Miyake A, Thesleff I and Itoh N: Sclerostin is a novel secreted osteoclast-derived bone morphogenetic protein antagonist with unique ligand specificity. J Biol Chem 278: 24113-24117, 2003.

30. van Bezooijen RL, Roelen BA, Visser A, van der Wee-Pals L, de Wilt E, Karperien M, Hamersma H, Papapoulos SE, ten Dijke P and Löwik CW: Sclerostin is an osteocyte-expressed negative regulator of bone formation, but not a classical BMP antagonist. J Exp Med 199: 805-814, 2004.

31. van Bezooijen RL, Svensson JP, Eefting D, Visser A, van der Horst G, Karperien M, Quax PH, Vrieling H, Papapoulos SE, ten Dijke P and Löwik CW: Wnt but not BMP signaling is involved in the inhibitory action of sclerostin on BMP-stimulated bone formation. J Bone Miner Res 22: 19-28, 2007.

32. Poole KE, van Bezooijen RL, Loveridge N, Hamersma $H$ Papapoulos SE, Löwik CW and Reeve J: Sclerostin is a delayed secreted product of osteocytes that inhibits bone formation. FASEB J 19: 1842-1844, 2005.

33. Hoang QQ, Sicheri F, Howard AJ and Yang DS: Bone recognition mechanism of porcine osteocalcin from crystal structure. Nature 425: 977-980, 2003. 
34. Price PA, Otsuka AA, Poser JW, Kristaponis J and Raman N Characterization of a gamma-carboxyglutamic acid-containing protein from bone. Proc Natl Acad Sci USA 73: 1447-1451, 1976.

35. Hauschka PV, Lian JB, Cole DE and Gundberg CM: Osteocalcin and matrix Gla protein: Vitamin K-dependent proteins in bone. Physiol Rev 69: 990-1047, 1989.

36. Hsieh JC, Kodjabachian L, Rebbert ML, Rattner A, Smallwood PM, Samos CH, Nusse R, Dawid IB and Nathans J: A new secreted protein that binds to Wnt proteins and inhibits their activities. Nature 398: 431-436, 1999.

37. Nakanishi R, Akiyama H, Kimura H, Otsuki B, Shimizu M, Tsuboyama T and Nakamura T: Osteoblast-targeted expression of Sfrp4 in mice results in low bone mass. J Bone Miner Res 23 : 271-277, 2008

38. Yamada A, Iwata T, Yamato M, Okano T and Izumi Y: Diverse functions of secreted frizzled-related proteins in the osteoblastogenesis of human multipotent mesenchymal stromal cells. Biomaterials 34: 3270-3278, 2013.

39. Takae R, Matsunaga S, Origuchi N, Yamamoto T, Morimoto N, Suzuki S and Sakou T: Immunolocalization of bone morphogenetic protein and its receptors in degeneration of intervertebral disc. Spine 24: 1397-1401, 1999.

40. Hiyama A, Sakai D, Tanaka M, Arai F, Nakajima D, Abe K and Mochida J: The relationship between the Wnt/ $\beta$-catenin and TGF- $\beta$ /BMP signals in the intervertebral disc cell. J Cell Physiol 226: 1139-1148, 2011.
41. Zhang R, Oyajobi BO, Harris SE, Chen D, Tsao C, Deng HW and Zhao M: Wnt/ $\beta$-catenin signaling activates bone morphogenetic protein 2 expression in osteoblasts. Bone 52: 145-156, 2013.

42. Burke JG, Watson RW, McCormack D, Dowling FE, Walsh MG and Fitzpatrick JM: Intervertebral discs which cause low back pain secrete high levels of proinflammatory mediators. J Bone Joint Surg Br 84: 196-201, 2002.

43. Weiler C, Nerlich AG, Bachmeier BE and Boos N: Expression and distribution of tumor necrosis factor alpha in human lumbar intervertebral discs: a study in surgical specimen and autopsy controls. Spine (Phila Pa 1976) 30: 44-54, 2005.

44. Le Maitre CL, Hoyland JA and Freemont AJ: Catabolic cytokine expression in degenerate and herniated human intervertebral discs: IL-1beta and TNFalpha expression profile. Arthritis Res Ther 9: R77, 2007.

45. Shamji MF, Setton LA, Jarvis W, So S, Chen J, Jing L, Bullock R, Isaacs RE, Brown C and Richardson WJ: Proinflammatory cytokine expression profile in degenerated and herniated human intervertebral disc tissues. Arthritis Rheum 62: 1974-1982, 2010.

46. Park JO, Lee BH, Kang YM, Kim TH, Yoon JY, Kim H, Kwon UH, Lee KI, Lee HM and Moon SH: Inflammatory cytokines induce fibrosis and ossification of human ligamentum flavum cells. J Spinal Disord Tech 26: E6-E12, 2013. 